\title{
A Historical Investigation of the Debates on the Invention and Invention Rights of Electron Microscope
}

\author{
Yaping Tao \\ College of Physical and Electronic Information \\ Luoyang Normal University \\ Luoyang, China 471934
}

\begin{abstract}
In the invention of the electron microscope, many engineers were involved almost simultaneously, and they all contributed in some way. Ernst Brüche was the first to construct the electron microscope by consciously using the electronic optical component in the cathode ray oscilloscope; Reinhold Rüdenberg was the inventor of the patent angle, and Ernst Ruska designed and manufactured the first electron microscope and the first commercial electron microscope was introduced.
\end{abstract}

Keywords—electron microscope; invention; dispute; priority

\section{INTRODUCTION}

Ernst Ruska, German, in 1986, shared the Nobel Prize in physics with two other scientists; at that time, the Nobel prize committee gave Ruska the eulogy of the award "for his contribution to the fundamental research of electron optics, and his design of the first electron microscope". We note that there was no word "invention" in the eulogy, which was not a casual, but a deliberate, deliberately evasive result, because Rüdenberg of Siemens was the inventor of patent angle. It is now generally believed that the electron microscope is the crystallization of the wisdom of many scientists, because of the fierce priority dispute, 55 years after the advent of the electron microscope, the 80 year old pioneers of the world were able to win the 1986 Nobel prize in physics

\section{PRELUDE TO THE INVENTION OF ELECTRON MICROSCOPE}

From the end of the 17 th century to the early 19 th century, the manufacture of microscope overcame the problems of color aberration, spherical aberration and instability, and finally evolved from the initial ornamental to a scientific tool worthy of the name. Abbe formula shows that the resolution limit of the optical microscope is proportional to the wavelength of the light wave, that is, the smaller the wavelength, the shorter the distance between the two points that the microscope can distinguish, or the higher the resolution of the microscope. At the end of the 19th century, the optical microscope was restricted by Abbe's theory of image formation, and the resolution of the microscope reached the theoretical limit of 0.2 micron, there are objects in the world that cannot be observed even with the highest resolution microscope at the time. Therefore, there was an urgent need for a new microscope with higher resolution. At the same time, the outbreak of foot-and-mouth disease and other infectious diseases, so scientists put forward the concept of "virus", it was a mystery that medical scientists and biologists are eager to unravel whether virus exists and cause disease transmission. In this context, it was particularly urgent to invent a new high resolution microscope, electron microscope is produced in such a background.

Electron microscope is an electronic optical instrument which uses electron beam and electron lens instead of light beam and optical lens according to the principle of electron optics so that the fine structure of matter can be imaged under very high magnification. Its history dates back to the end of the 19th century and is closely related to the development of cathodic ray oscilloscopes. In 1897, Karl Braunn, a German physicist, designed and manufactured the first cathode ray tube, and then used axisymmetric magnetic or electrostatic fields to focus on the cathode ray and made a cathode-ray oscilloscope, the technical conditions are prepared for the birth of electron microscope. In 1923, Louis De Broglie, a French physicist, proposed the idea of wave particle duality of electrons, and then he succeeded in deducing the correct expression of electron wavelength: $\lambda=\frac{h}{m v}$ ( $\mathrm{m}$ is the mass of the electron, $\mathrm{v}$ is the velocity of the electron, and $\mathrm{h}$ is the Planck constant). Both the mass and velocity of electrons in this formula are related to the accelerating voltage of the electron, that is, if the electron moves rapidly in an electric field, raising the voltage to a certain value, the wavelength of the electron can reach $1 / 1000$ nanometers or smaller. This is the "perfect light" source needed to make a high-resolution microscope, so can an electron beam be focused by a lens like light? Or is there an electronic lens that corresponds to the function of an optical glass lens? The answer is no.

In 1926, Austrian physicist named Erwin Schrödinger successfully deduced the equation of motion of electron wave in electromagnetic field, which illustrated the fact that the dynamical trajectory of electron propagation corresponds to the concept of optical system. If it is assumed that the refraction constant of light wave propagating medium (such as 
glass) is proportional to the velocity of electron motion, the propagation of electron wave in electromagnetic field is comparable to that of light wave (light wave is a kind of electromagnetic wave) propagating in medium. This important comparability raises the question that since the light wave can be focused by the lens, the electron beam should also be able to focus, but how can it be achieved?

In 1926, without knowing the work of Schrodinger, Hans Walter Hugo Busch published several papers on magnetic focusing, pointing out that electron beams can be focused through axisymmetric electromagnetic fields, so they can make use of electronic imaging, this is the theoretical preparation for the electron microscope. Since the main factor limiting the resolution of the microscope is the wavelength of the light, the wavelength of the electron beam is several orders of magnitude smaller than the wavelength of the light wave, so it is expected that the resolution of the electron microscope can be much higher than that of the optical microscope. An axisymmetric magnetic field acts as a lens on the electron beam.

From 1924 to 1927 , the fluctuation of electrons, the very small wave length of electrons, the realization of electron beam focusing, and the establishment of the theory of electron propagation dynamics all made electron beam replace the beam, the idea of using electromagnetic lenses instead of glass lenses to produce ultra-high resolution microscopes had emerged.

\section{IMPORTANT FIGURES IN THE COURSE OF THE INVENTION OF ELECTRON MICROSCOPE}

\section{A. The Designer of the First Electron Microscope}

The designer of the first electron microscope is now recognized as a German engineer, physicist Ernst Ruska. In 1927, Ruska joined the team of Dr Max Knoll, a Berlin high engineer, a simple cathode ray oscilloscope based on the principle of electron beam focusing is improved to a high performance cathode ray oscilloscope. The first thing he did in 1928 was to prove that the magnetic field produced by an electrified coil that was put forward by Bosch had an effect on electron ray focusing. In this work, Ruska realized that if an iron cap was added to the coil, the focal length of the electromagnetic lens could be shortened. Inspired by this, Ruska made a true electromagnetic lens, thus opening the electron microscope process. This work laid the foundation for its successful development of the electron microscope the first person.

Then, Ruska, Bodo Von Borries and Knoll began to transform the cathode - ray oscilloscope into an electron microscope, which was successful in 1929, which is an electronic microscope with a single lens. The light source part is a cathode ray tube, and the electron beam emitted by it can be focused by a magnetic field electron lens made of an electrified coil, behind the lens there is a sample and a circular aperture, the resulting image can be displayed on a fluorescent screen. The whole system, from the light source to the sample to the screen, is arranged on a line, that is, the microscope is lying. Although the remolding instrument is mainly cathode- ray oscilloscope, it proves the feasibility of electron beam microscope imaging.

On April 7, 1931, Ruska and Knoll succeeded in making the first real electron microscope, this instrument has two magnetic lenses, which can be magnified by 17 times after secondary amplification. Their invention was reported in the German Journal of Physics on April 28, 1931.On June 4, 1931, Knoll gave a speech on the current progress of the cathode-ray oscilloscope in high engineering Berlin, showing the electron microscope. ([7], 128) Unexpectedly, their invention was not only promptly recognized by academia and relevant departments, but also fell into a long dispute over patent rights.

Ruska insisted on working hard, in 1932, he and his collaborator, Bodo Von Borries, developed an electronic microscope of the all-metal mirror, using a magnetic coil encased in an iron shell as a magnetic lens, and filed a German patent for it on March 17, 1932. (German patent number: $680,284)$ The electron microscope he invented is called a magnetic field lens because it uses the magnetic field produced by the electrified coil to focus the electron beam. In November 1933, Ruska made an electron microscope with a magnification of 12000 times independently, and exceeded the limit resolution of optical microscope for the first time $(0.2$ microns). Thereafter, the electron microscope study was terminated because of the lack of financial support.

\section{B. Inventor of Patent Angle of Electron Microscope}

Just four days before Knoll's speech, that was, on May 30, 1931, Reinhold Rüdenberg, chief engineer at Siemens in Germany, submitted a patent application for the combination of several magnetic fields and electrostatic field lenses in the design of electron microscope, and then to the United Kingdom, The United States and France filed similar patent applications. ([5], 57) Rüdenberg himself had not previously proposed any report on the results of electromagnetic lens imaging, and after applying for a patent, he had "kept it confidential" and had not published any related results. Therefore, the patent application was questioned, and General Electric German (Shorter form: AEG) was more strongly opposed. However, in December 1932, the French Patent Office approved Rüdenberg's application and approved by the United States Patent Office in October 1936, two patents in 1953 and 1954 were approved by the Federal German patent office successively, So that Rüdenberg became the inventor of the electron microscope in the history of patents, Rüdenberg emigrated in 1935 and did not actually study the electron microscope.

\section{The Earliest Conceiver of the Electron Microscope}

Ruska also faced the difficulty of being accused of not being the earliest conceiver of the electron microscope. Ernst Brüche , a German general electrical company ( AEG ), wrote a short essay in November 1931 that claimed that AEG was committed to the study of electron microscopy for more than a year and then introduced a prototype of an electron microscope, which was horizontal and was the same electron microscope as the Crusoe ,the difference is that it does not use a cathode ray tube as an electron source, but rather uses a tungsten filament to emit electrons with a magnification of 
several tens of times. And in fact Brüche did report on the intentional use of electro-optical components in cathode-ray oscilloscopes as early as 1930, but AGE introduced the prototype of the electron microscope in November 1931. [9, 137]

\section{Other Researchers}

Ardenne (Manfred von Ardenne, 1907-1997) published the first electronic microscope monograph in history in 1940; and in 1938, he published an article that detailed discussed the limiting factors for the resolution of electron microscope and the causes of the aberration of electron microscope and so on; in 1940, Adenauer made a fully functional electron microscope, which can be used to observe bright and dark field images. In 1936, Bosch published the article for the first time to remind people to pay attention to the relationship between electron microscope imaging and electron diffraction, and demonstrated the selected area electron diffraction for the first time. The Fresnel diffraction stripes at the edge of the sample were also discovered by Bosch in 1940 and a correct explanation of the cause is given. German General Electric Company Marr invented Electrostatic Field Electron microscope.

\section{A DiSPUTE BETWEEN THE TWO CAMPS}

The argument became more and more intense, from the initial personal priority argument to the priority argument between the two camps.

In the early 1930s, Siemens had an unofficial agreement with AEG, in which it promised not to enter the field of electronics and optics, which was occupied by laboratories led by AEG's Brüche et al. As Ruska joined Siemens in 1937, Siemens began to enter the field of electronics and optics. Siemens has been involved in the development of electron microscopy because of a patent application for the electronic microscope in May 1931, however, Rüdenberg's patent application seemed to be further deduced from the inspiration of information obtained from other sources, and there was no subsequent experimental data or report support since the patent application. So we can see that Siemens' electron microscope patents were just an empty shelf before Ruska and Boris joined them in 1937, and even so, for Ruska and Boris, joining Siemens would be a better form of patent for their research, because Rüdenberg's patent included the design ideas of Ruska's magneto electron microscope and Brüche's electrostatic field microscope, they belonged to the same company, and AEG launched an opposition movement to avoid impeding research because of concerns about patent infringement, as it was initially the work of AEG researchers. But Siemens believes that AEG had not made a special contribution in the years since it prevented Siemens from entering electron optics, just repeating it, not seizing the opportunity, and now the electron microscope was a ripe fruit, which must be picked. Siemens managed to buy or share many important patents. The form of patents, though difficult, is beneficial to managers. Siemens not only had the patent of Rüdenberg, but also had the patents of $\mathrm{Lu} \mathrm{Ca}$ and Boris, and some other researchers' patents. Such as Adenauer's patent rights and innovation rights were embodied in Siemens microscope. Rüdenberg's patents were especially critical, were protected in a wide range of areas, not only in magnetoelectric microscope, but also in electrostatic electron microscope. Although the patent was approved only in Germany after the war, it provided a protection space for Siemens microscope. Siemens was far sighted and fully aware of the wide market value of electron microscopy. In 1937, Siemens set up an electron-optics laboratory for the two men in Berlin to develop an electron microscope. They succeeded in obtaining a series of patents related to the electron microscope (United States Patent number: 2,266,082; 2,267,137; 2,301,975; 2,305,458; $2,370,373$ et al). In 1939, Siemens made a practical commercial electron microscope, the resolution of which was up to $30 \mathrm{~A}$ and put into mass production, which marked the arrival of the commercial era of electron microscope. In order to expand the field of research, Siemens set up a visiting laboratory in 1940. He invited scientists from all over the world to carry out electron microscopy research with the suggestion of Ruska and Boris. This measure is also important for the application and popularization of electron microscopy. By the end of 1944, there had been more than 200 articles related to the laboratory, and by early 1945 about 35 institutions had installed electron microscopes designed by Ruska. [6] Hans Boersch, Hans Mahl and others of AEG Company made the first electrostatic field electronic lens by using the electrostatic field in 1939, they were patented in 1941 (US patent number: 2249453) and were used to compete with the magnetic field electron microscope of Ruska. The battle for priority between the two camps sparked a fierce debate in Germany in 1939 during World War II. [8]

Both camps published a series of articles to refute each other's claims about electron microscope invention and the priority of electron microscope theory, and the controversy lasted for more than 5 years, AEG suffered so badly in the war that it had to end the long electron microscope priority debate after the war. After World War II, Siemens did not lose much, and after being repaired, it continued to develop in electron microscope manufacturing. It is worth mentioning that the Prussian Academy of Sciences, Germany's top academic organization, tried to calm the debate during the priority debate between the two camps, the 1941 Leibniz Silver Medal was awarded to seven individuals who contributed to the development of the electron microscope: Brush, Marl, Bosch, Knoll, Ruska, Boris and Adenauer. [9].

\section{INSPIRATION FROM THE INVENTION OF ELECTRON MICROSCOPE}

Who did rights of the invention of electron microscope belong to? Ruska's submission of April 28, 1931 did not use the terms such as electron optics, electron lens and electron microscope. Rüdenberg first proposed an electron microscope in his patent application on May 30, 1931, but made no mention of electron optics, and Ruska began to use the term electron optics in a paper they submitted on September 10, 1931.The inconsistency of terms in the early development of these electron microscope left some unstable factors, and also led to the fierce debate about the later priority.

For this Ruska's explanation was: not wanting to be accused of showing off, Knoll and I agreed to avoid the use of 
the term electron microscope in Knoll's June 1931 speech on the development of cathode-ray oscilloscopes, he also described for the first time the details of my electron-optics research. This statement was not convincing. Because at that time Ruska did not know de Broglie's idea that is electrons were waves. Even after he knew it, he was annoyed that the electron microscope was restricted by visible light and its resolution could not be improved. From the De Broglie equation, the wavelength of electrons is 5 orders of magnitude smaller than that of light, and at this case Ruska was determined to study electron microscopes. In 1932, they also predicted that the resolution of the electron microscope was 2.2A, this value was obtained in the experiment 40 years later. This fact suggested that Ruska didn't realize that the instrument which can amplify the sample was comparable to the brightness of an optical microscope. To be precise, they were unaware of the electron beam = beam and the short coil = lens. Perhaps he was aware of De Broglie's electronic wave, and perhaps after hearing about Rüdenberg's patent application, he was moving towards a new field .In fact, in his presentation and speech in Berli High engineer on June 4, 1931, it was still thought that what was shown was a measuring instrument based on anodic ray oscilloscope, therefore, the authors prefer that they do not realize that the electron microscope is comparable to the optical microscope. Another successful development, immediately announced, is to ensure the priority of research results, afraid of being said to show off, not to mention the electron microscope cannot be justified. It is possible to make a veiled introduction as well as to ensure priority and fear that others will rush into this new field, but they should think that even if they don't mention the word, other scientists, such as Rüdenberg, would be inspired as well, it was suspected of having heard the report in advance and patented the microscope. In fact, Rüdenberg's assistant, Steinbeck, visited Knoll's lab in 1931 and saw a speech by Knoll in Berlin High engineer on June 4, 1931, reporting to him, Steinbeck thought that Rüdenberg was inspired by the report and came up with the concept of an electron microscope.

Ruska made the first electron microscope while studying the cathode-ray oscilloscope, but he didn't realize it. Brüche was conscious of making an electron microscope, and reported his own ideas, but Ruska did not see the report. When Rüdenberg heard about Ruska's design, he realized it was a whole new field, after deep thinking, Rüdenberg applied for a patent, but didn't do it, and he probably saw the report of Brüche. Rüdenberg applied for the patent, making it difficult for Ruska to make an electron microscope, although he later applied for a lot of patents, he was not the inventor of the patent angle forever. For this reason, he argued with Rüdenberg about the priority, the effect of the argument was that Rüdenberg's patent hadn't been approved in Germany, Ruska was forced to join Siemens in 1937, when he emigrated, but his patent remained. Because of the same company, Rüdenberg was no longer opposed to Rüdenberg's patent, but Brüche of the AEG company insisted on opposition because Rüdenberg's patent included Brüche's design idea of the electrostatic field microscope, if Rüdenberg 's patent was approved, affecting the development of Brüche microscopes. So the debate lasted until the end of World War II, when the
AEG Company launched the electronic microscope manufacturing industry.

\section{CONCLUSION}

Although many people have contributed to in the process of actual invention of the electron microscope, it is only a guess of who influences who based on available data. But one thing is for sure: there is no doubt that Ruska is the first design and manufacture of electron microscope. It is also worth mentioning that, although in $30 \mathrm{~s}$, magnetic field electronic lenses and electrostatic field electronic lenses were equally interesting and coexisted in the world, but as the research went deep, the electrostatic field microscope has short service life due to the easy contamination of the electron gun, the instability of the electron beam and the larger aberration are gradually eliminated. Modern electron microscopes are all magnetic field electronic lenses, similar to those designed by Ruska and others in the early 30s. Research results can only be widely shared in order to maximize benefits and services to mankind. Some attempts to monopolize the idea have prevented scientific progress.

\section{ACKNOWLEDGMENT}

Acknowledgements: This work is supported by Key scientific research Projects for Higher Education in Henan Province of China (No. 17A140010).

\section{REFERENCES}

[1] Zhang Xiaofeng, A clear Nano-World: the Millennium pursuit of the Ultimate goal of Microscopy,Tsinghua University Press, 2005. 章效 锋, 清晰的纳米世界——显微镜的终极目标的千年追求, 清华大学 出版社, 2005

[2] Hogg, Jabez, The microscope: its history, construction, and applications, London, 1856

[3] Guo Kexin. The history of metallography(6):Application of Electron microscope in Materials Science[J]. Journal of material science and Engineering, 2002, 20(1):5-10. 郭可信. 金相学史话(6): 电子显微镜在 材料科学中的应用 [J]. 材料科学与工程学报, 2002, 20(1):5-10.

[4] Guo Yiling, Shen Huijun,. Nobel prize in physics, Higher Education Press, 1999. 郭奕玲, 沈慧君. 诺贝尔物理学奖, 高等教育出版社, 1999

[5] William J. Croft, Croft W J. Under the Microscope: A Brief History of Microsc [M]. Published by World Scientific Publishing Company, 2014

[6] Gosta Ekspong, Nobel Lectures in Physics 1981-1990[M]. Published by World Scientific Publishing Company, 2002

[7] Peter W. Hawkes, Advances in Electronics and Electron Physics[M]. ByPublished by Academic Press, 1992

[8] James Hogg, Scientific Research In World War II: What Scientists Did in the WarBy Ad Maas, Published by Taylor \& Francis, 2008

[9] Mulvey T, Hawkes P W. The growth of electron microscopy[M] Academic Press, 1996. 